$1-1-2011$

\title{
Update on pain management in sickle cell disease.
}

Samir K Ballas

Thomas Jefferson University

Follow this and additional works at: https://jdc.jefferson.edu/medfp

Part of the Medical Genetics Commons

Let us know how access to this document benefits you

\section{Recommended Citation}

Ballas, Samir K, "Update on pain management in sickle cell disease." (2011). Department of Medicine Faculty Papers. Paper 65.

https://jdc.jefferson.edu/medfp/65

This Article is brought to you for free and open access by the Jefferson Digital Commons. The Jefferson Digital Commons is a service of Thomas Jefferson University's Center for Teaching and Learning (CTL). The Commons is a showcase for Jefferson books and journals, peer-reviewed scholarly publications, unique historical collections from the University archives, and teaching tools. The Jefferson Digital Commons allows researchers and interested readers anywhere in the world to learn about and keep up to date with Jefferson scholarship. This article has been accepted for inclusion in Department of Medicine Faculty Papers by an authorized administrator of the Jefferson Digital Commons. For more information, please contact: JeffersonDigitalCommons@jefferson.edu. 


\title{
As submitted to:
}

\author{
Hemoglobin
}

\section{And later published as:}

\section{UPDATE ON PAIN MANAGEMENT IN SICKLE CELL DISEASE}

\author{
Volume 35, Issue 5-6, October 2011, Pages 520-529
}

\section{DOI: $10.3109 / 03630269.2011 .610478$}

PRESENTED AT THE

INTERNATIONAL CONFERENCE

ON HEMOGLOBIN DISORDERS

KUWAIT, February 5-7th, 2011

Samir K. Ballas

Department of Medicine, Cardeza Foundation, Jefferson Medical College, Thomas Jefferson University, Philadelphia, Pennsylvania, USA

Declaration of Interest: The authors report no conflicts of interest. The authors alone are responsible for the content and writing of this article.

Received 23 March 2011; Accepted 23 March 2011.

Address correspondence to Samir K. Ballas, M.D., F.A.C.P., Department of Medicine, Cardeza Foundation, 1015 Walnut Street, Philadelphia, PA 19107, USA; Tel.: +215-955-5266, extension 98686; Fax: +856-795-0809; E-mail: samir.ballas@jefferson.edu

SHORT TITLE: Pain Management in Sickle Cell disease 
PRESENTED AT THE

INTERNATIONAL CONFERENCE

ON HEMOGLOBIN DISORDERS

KUWAIT, February 5-7th, 2011

\title{
UPDATE ON PAIN MANAGEMENT IN SICKLE CELL DISEASE
}

\author{
Samir K. Ballas \\ Department of Medicine, Cardeza Foundation, Jefferson Medical College, Thomas Jefferson \\ University, Philadelphia, Pennsylvania, USA
}

\begin{abstract}
Acute pain is the hallmark of sickle cell disease and is the most common cause of hospital admissions. Tissue damage due to vaso-occlusion releases numerous inflammatory mediators that initiate the transmission of painful stimuli that culminate in the perception of pain. The acute sickle cell painful crisis evolves along four phases. Each phase is coupled with changes in certain markers of the disease. Hospital readmission occurs within 1 week in about $16 \%$ of discharged patients and within 1 month in about $50 \%$ of discharged patients. Failure to treat acute pain aggressively may lead to chronic pain syndrome which, in turn, initiates neuropathic pain. Management of sickle pain is primarily pharmacological in nature and opioids are the analgesics used most often. Adverse effects of opioids include histaminergic, excitatory, dopaminergic and proserotonergic effects. Cellular and molecular mechanisms of opioids explain individual differences among patients and justify the use of individualized treatment plans.
\end{abstract}

Keywords Sickle Cell Disease, Sickle cell Anemia, Sickle Cell Pain, Pain, Pain Management

\section{INTRODUCTION}

Sickle cell disease in general and sickle cell anemia (SS) in particular is a unique, paradoxical and complex hematological disorder (1). On the one hand it is an inherited chronic disease and yet, on the other hand, its most common and serious complication is recurrent attacks of acute painful crises that often require treatment with parenteral opioids, especially in adults, in the Emergency Room (ER) and/or the hospital (2). Some providers, especially non hematologists, may be confused by this paradox of the disease and may consider chronic pain as the major manifestation of this chronic disease that should be treated in the clinic or office with oral analgesics. Moreover the complexity of this disease is due to the fact that it is a conglomerate of at least four disorders encapsulated in one (2). These include: anemia and its sequelae, pain syndromes, organ damage/failure and co-morbid conditions. Anemia is hemolytic in nature and is often associated with cholelithiasis due to bilirubin stones. It may be exacerbated by aplasia (3) or hyperhemolysis (4) and may require frequent blood transfusions leading to iron overload (5). Moreover severe hemolysis may be associated with pulmonary hypertension, priapism and leg ulcers (6). All organs may be adversely affected by sickle cell disease. The organs that are most commonly affected include the spleen, the central nervous, pulmonary, hepatobiliary, genitorenal, and musculoskeletal systems. This presentation will focus on pain syndromes and 
their management as described below.

\section{PAIN SYNDROMES}

Sickle cell pain syndromes include an unusual triumvirate of acute, chronic and neuropathic pain that occur sequentially or simultaneously with age as will be described below. Unlike other diseases associated with chronic pain such as osteoarthritis, rheumatoid arthritis, fibromyalgia and complex sympathetic dystrophy, sickle cell acute pain manifests itself in infancy and continues to recur throughout the life span of the affected patient. With age acute pain retains its unpredictable relapses and spawns chronic pain as a new partner in the rhapsody of pain and suffering. Chronic pain may evolve into neuropathic pain. Acute pain, however, dominates the clinical picture and requires urgent treatment with parenteral opioids in the ER and/or hospital. The chronic pain syndromes due to the other disorders mentioned above rarely, if ever, require management similar to that of acute sickle cell pain. They are usually treated as out patients with oral analgesics. Nevertheless, they do encounter occasional negative attitudes and disparities from some providers, albeit less frequent and less combative than what patients with sickle cell disease encounter (7).

"Breakthrough" pain is another kind of pain often referred to by care providers following patients with sickle cell disease. Literally this term means the act of breaking through pain relief. Originally, this term was introduced by Coluzzi et al. (8) for patients with cancer pain and was defined as a flair of sudden pain in patients with cancer pain that were maintained on a stable dose of oral analgesics to achieve adequate relief. Such flair is usually sudden, and incidental, precipitated by movement and lasts from a few seconds to a few hours. Recommended management includes the administration of short-acting analgesics via a route that achieves immediate relief such as parenteral or transmucosal. Details of the definition and management of breakthrough pain are controversial to date and its application to other types of pain seems unjustified. Health care providers treating patients with sickle cell pain use the term "breakthrough" pain loosely for any pain that occurs in patients taking daily analgesics for chronic pain and treat it with short-acting oral analgesics that are the same or different than the long-acting analgesics the patients are already taking. Moreover, the short-acting analgesic is often given several times a day in cumulative excessive doses that are as high as or even higher than the daily dose of the long-acting opioids the patients are already taking. Thus, this kind of practice is not for breakthrough pain but rather an administration of extra or rescue doses of analgesics for pain that is inadequately treated in the first place and implies that the dose of the long-acting analgesic used should be increased to achieve better pain relief.

\section{PATHOPHYSIOLOGY OF SICKLE CELL PAIN}

Acute Pain

Clinically acute sickle pain is typically sharp and/or throbbing in nature, of sudden or gradual onset. It may last from minutes to weeks in duration. The average duration of an acute painful crisis in adults, based on the length of hospital stay, is about 7 days $(2,9)$. Acute sickle cell pain is believed to be secondary to vaso-occlusion by sticky sickled erythrocytes that adhere to vascular endothelium. Vascular occlusion leads to ischemia and consequent damage of the 
tissues supplied by the occluded vessel. Tissue damage, in turn, creates a state of inflammation with the release of several inflammatory mediators. The chemical energy created by inflammation is transformed into an electrical impulse of pain transmitted along peripheral nerves (A $\delta$ (Author: please clarify this) and $\mathrm{C}$ fibers) to the dorsal horn of the spinal cord. The impulse ascends along the contralateral spinothalamic tract to the thalamus which, in turn, interconnects reversibly with the limbic system and other regions of the central nervous system (CNS). At the same time the CNS tries to inhibit the transmission of the painful stimulus with endogenous serotonin and epinephrine at the level of the dorsal horn via a genetically determined descending pathway that starts in the periaqueductal gray matter of the midbrain. The modified electrochemical pain impulse is eventually sent to the cerebral cortex where it is perceived as pain. Thus, this sequence of events illustrates that pain is subjective in nature and is the end result of a complex interplay among enhancing and inhibiting genetically determined factors at the level of the CNS.

Each inflammatory mediator released peripherally after tissue damage binds to a specific receptor on the neurons of peripheral nerves (10). These neurons are crowded with multiple receptors for inflammatory mediators and for descending inhibitory pathways from the CNS. This state of affairs of one neuron with multiple receptors implies that inhibition of the transmission of the painful stimulus at the level of the peripheral nerve entails the blocking of all these receptors. It is impossible to find one drug that blocks all these receptors. Blocking the transmission of the painful stimulus peripherally requires the utilization of more than one analgesic capable of blocking all or most of the neuronal receptors.

\section{Chronic Pain}

Clinically, chronic pain is simply pain that does not go away for 3 or more months. It is usually described as pain that is deep, nagging and achy in nature that is there all the time. Chronic sickle cell pain is of two types. The first is due to obvious objective signs including leg ulcers and avascular necrosis. The second type is due to persistent or frequently recurrent acute painful events. Recurrent attacks of acute severe painful crises, especially if not adequately treated, lead to the creation of chronic pain syndrome. The pathophysiological events of this transformation are not well understood. With the onset of chronic pain there seems to be a process of "rewiring" the brain where the threshold for pain perception is lowered so that ambient environmental stimuli that are normally painless or mildly painful induce the perception of severe pain. Hyperalgesia in this context is the perception of severe pain generated by stimuli that are normally mildly painful and allodynia is the perception of severe pain by stimuli that are normally painless $(2,7,11,12)$.

Neuropathic Pain

Clinically, neuropathic pain is usually described as numb, tingling, lancinating, shooting or paroxysmal in nature associated with a sensation of pins and needles. Its severity is also enhanced by exposure to either cold or heat. This pain was believed to be secondary to nerve injury whether peripherally or centrally. This definition has recently been modified by the International Association for the Study of Pain (IASP) to include injury and dysfunction of nerves as causes. Sickle cell neuropathic pain is also of two types. The first is due to obvious 
objective signs due to tissue damage following vaso-occlusion of blood vessels of nerves (vasa vasorum) such as mental nerve neuropathy and spinal cord infarction. The second seems to be consequent to chronic pain. To that end, persistent chronic pain and/or its management seem to cause the perception of neuropathic pain. The pathophysiological events leading to this transformation are also not well understood. Activation of the glia seems to be the root cause of neuropathic pain. The mechanisms of glial activation are beyond the scope of this presentation and are available in the listed references $(2,7,11,12)$.

\section{Management of Sickle Cell Pain}

Effective management of sickle cell pain is complex and entails a thorough understanding of the issues that are associated with the treatment of pain in an incurable chronic disease (1-4). Major prerequisites for an effective and rational management of sickle cell pain pertain to the patient, the pathophysiology of the disease, the pharmacology of analgesics, and the attitude of the health care providers. A patient is a unique human entity. The more a provider knows the patient, the more effective pain management becomes. Knowledge of the patient should not be limited to age, sex, precise diagnosis, complications and previous pain management methods. It should also take into consideration the biopsychosocial fabric of the patients' lives, including their level of education, employment status, occupation, family structure, source of income, ethnicity, housing conditions, fears, religion, beliefs, habits, hobbies, and perception of the severity and prognosis of their disease. This approach allows the physician to individualize pain management and avoid unfounded generalizations about patients and their consumption of opioid analgesics. Such generalizations, for instance, may result in over sedation of a patient naive to opioids or in under treatment of a patient tolerant to them.

\section{Non Pharmacologic Management of Pain}

Nonpharmacologic management of pain includes the use of heat or cold packs, distraction, relaxation, massage, music, guided imagery, self-hypnosis, self-motivation, and acupuncture. Although there are no controlled clinical trials of the efficacy of these methods in the management of sickle cell pain, there are many anecdotal reports of their efficacy in pain management, both by patients and providers (2). These approaches may increase the level of endogenous endorphins that are known to have analgesic effects similar to those of exogenous opioids but without the side effects associated with opioids $(11,12)$.

\section{Pharmacologic Management of Pain}

Pharmacologic management of sickle cell pain includes three major classes of compounds: non opioids, opioids, and adjuvants $(12,13,(?) 63(?))$. Non opioids include acetaminophen, non steroidal anti-inflammatory drugs (NSAIDs), topical agents and corticosteroids. Most commonly used opioid analgesics include the mu-agonists, although the mixed agonist/antagonist buprenorphine and the partial agonist pentazocine have achieved some popularity, especially in Europe. Adjuvants commonly used in the management of sickle cell pain include antihistamines, benzodiazepines, antidepressants, anticonvulsants and phenothiazines. The short-acting opioids are usually used to treat acute pain whereas controlled-release opioids and long-acting opioids are used in the management of chronic pain. 
Pain Management of Out Patients

Management of patients with sickle cell disease as out patients in the clinic or office is extremely important and is the basis on which future treatments and interventions are based. Patients should be followed by the same providers in order to maintain continuity of care. The most important aspect of out patient management is the collection of steady state data that include detailed medical history, physical examination, known complications, medications, and comprehensive laboratory data. Management of exacerbations in the ER or in the hospital depends heavily on knowing the steady state parameters of the patient in question. It is highly desirable that patients be seen and evaluated in the office or clinic by a social worker and a psychologist or psychiatrist. It is in the out patient set up, that details of care in general and in the ER, day unit, and hospital are explained and discussed. The pros and cons of all medications the patient is taking will be reviewed. Prescriptions will be given as needed. Vaccines will be administered when required $(2,13-16)$.

In the out patient setting, patients should be empowered to cope with their disease and be authorities on its manifestations that apply to them individuality. This includes education about sickle cell disease, its genetic basis, inheritance and family counseling; adherence to regular schedule of medical follow-up; avoidance of situations that exert an adverse effect on their disease and adoption of those activities of daily living that are beneficial to them; knowing their rights and responsibilities as patients with sickle cell disease when dealing with care providers, medical facilities and the workplace; and participation in local support groups and communication with community leaders and advocates.

Management and follow-up of outpatients in the office and clinic should culminate in an individualized treatment plan for each patient. Such a plan should summarize pertinent aspects of the medical history, physical examination, laboratory data, complications and treatment plans as out patients, in the day unit, $\underline{\mathrm{ER}}$ and the hospital. In some places, the treatment plan may be transformed into an ID card to be carried by the patient and presented to care provider as needed (17).

Pain Management in the Emergency $\underline{\text { Room }}$

Treatment of acute sickle cell painful episodes in the ER follow similar principles of thorough assessment, treatment with analgesics/adjuvants, coordination of care, monitoring, outcome and disposition. The major problem in the ER is the length of waiting time to initial analgesia which could be up to several hours. Needless to say, that waiting while in pain constitutes a stressful situation that could worsen the painful crises and render it no longer amenable to resolution and discharge from the ER but to hospital admission. Many ERs are in the process of determining and implementing strategies that could shorten the time to initial treatment $(2,13-15)$.

Specific treatment in the ER should be based on the history or the computerized version of the treatment plan if available. Usually analgesics are given individually every 2 hours for a total of three doses. Adjuvants may also be given intravenously or orally as needed. If the pain is resolved or reduced to a level with which the patient is comfortable, the patient is discharged 
with instructions for follow-up by the primary care physician (PCP) and/or hematologist. Otherwise the patient will be admitted to the hospital.

Management of Sickle Cell Pain in the Hospital

Successful management of the acute painful crisis in the hospital should include the following steps $(2,13,14,18)$ : (1) Multidimensional assessment to determine the location of pain, its intensity, its quality, precipitating factors, modifying factors, triggers, and to determine mood, pain relief and sedation in addition to checking the vital signs including pulse oximetry. (2) Choice of analgesics (opioids/non opioids), adjuvants, and hydration if needed; such choices are individualized based upon the past medical history and the assessment of the patient in question. If the acute painful episode is superimposed on chronic pain for which the patient is taking longacting/controlled-release opioids with short-acting opioids for rescue doses in between, keep the long-acting/controlled-release opioids the same and discontinue the short-acting ones. (3) Determination of the route and method of administration of analgesics. These, again, should be individualized; parenteral analgesics are usually administered either on a fixed schedule or via a Patient controlled analgesia (PCA) pump. (4) Titration of the dose of analgesics to achieve relief with which the patient is comfortable. (5) Maintenance of the dose that achieves adequate relief. Consider opioid rotation, i.e., change the opioid chosen initially to an equianalgesic other opioid if its usage does not achieve or maintain relief. (6) Plan to treat neuropathic pain if present, and side effects of the crisis or the analgesics, if present. (7) Tapering the dose of analgesics once the patient uses the PCA pump less frequently or the intensity of pain decreases by two or more points. (8) Gradual switching to oral analgesics using tables of equianalgesic doses as an initial guide. One example would be to decrease the parenteral dose by $25 \%$ and replace it with an equianalgesic oral dose. The latter should be adjusted according to its effect to achieve pain relief with which the patient is comfortable. (9) Prevention of withdrawal by using either clonidine patch or methadone. (10) Plan for discharge and follow-up.

\section{Opioid Treatment Guidelines}

Management of outpatients with pain using oral opioids should follow the recently published recommendations established by the American Pain Society and the American Academy of Pain Medicine (19). These recommendations emphasize minimizing the risks associated with prescribing opioids within the framework of optimizing analgesia to achieve adequate pain relief for patients using opioids on a regular and chronic basis.

\section{Optimize Analgesia}

Management of patients with sickle cell pain with chronic opioids can be effective if the drug is carefully selected and if the patients with sickle cell pain are monitored despite limited evidence in the literature. Failure to optimize analgesia may cause seemingly aberrant behavior such as pseudo-addiction (20) or serious maladaptive behavior such as the use of illicit street drugs in order to achieve adequate pain relief (21).

Minimize Risk

It is well known that opioids are associated with serious side effects and outcomes related to 
abuse, misuse and diversion of prescribed opioids. To that end, providers should follow the recommended guidelines to minimize the risks associated with opioids. Recommended procedures to minimize the risk of abuse, misuse and diversion include the following (20): (1) Obtain detailed history and physical exam on every patient enrolled in your practice. (2) Document all subsequent encounters with the patient including progress notes, vital signs, laboratory data, changes in physical examination if any, changes in clinical picture if any, prescriptions written, etc. (3) Establish a consent (or agreement) form and individualized treatment plan for every patient and revise periodically as needed. (4) Prescribe opioids for 1 month at a time. (5) Establish refill policy for every patient. For example: prescription refills without seeing the patient will be approved on two consecutive occasions only. Additional refills will not be approved until the patient is seen, examined and evaluated by the provider. (6) Do pill and patch count whenever the patient is seen in person. (7) Non compliance or breach of the agreement form and treatment plan must trigger counseling and discussions with the patient to emphasize the seriousness of these deviations and to revise the plans if needed. (8) Do random urine drug testing using zero cutoffs for opioids. (9) Learn how to interpret the results of the screening test for urine drugs and/or seek help in their interpretation. Perform confirmatory testing if needed. (10) Document, document and document all details in the patient's file.

\section{CONCLUSIONS}

Pain is the hallmark of sickle cell disease and the most frequent reason for hospital admissions. Pain sensation results from a very complex and interactive series of mechanisms integrated at all levels of the nervous system: from the peripheral nerve fibers, via the dorsal root ganglion and via the dorsal horn of the spinal cord, the thalamus and the limbic system to the higher cerebral cortex where pain is perceived. Recently, there have been major advances in understanding the pathophysiologic mechanisms of pain sensation and its complications as well as newer approaches that impact the assessment and management of patients with sickle cell pain. Progress in this area may minimize the pain and suffering of patients with sickle cell disease and improve their quality of life.

\section{REFERENCES}

1. Ballas SK. Current issues in sickle cell pain and its management. Hematology Am Soc Hematol Educ Program. 2007:97-105.

2. Ballas SK. Sickle Cell Pain. Progress in Pain Research and Management, Vol. 11. Seattle: IASP Press, 1998.

3. Zimmerman SA, Davis JS, Schultz WH, Ware. Subclinical parvovirus B19 infection in children with sickle cell anemia. J Pediatr Hematol Oncol. 2003;25(5):387-389.

4. Ballas SK, Marcolina MJ. Hyperhemolysis during the evolution of uncomplicated acute painful episodes in patients with sickle cell anemia. Transfusion. 2006;46(1):105-110.

5. Karam LB, Disco D, Jackson SM, et al. Liver biopsy results in patients with sickle cell disease on chronic transfusions: poor correlation with ferritin levels. Pediatr Blood Cancer. 2008;50(1):62-65.

6. Kato GJ, Gladwin MT, Steinberg MH. Deconstructing sickle cell disease: reappraisal of the role of hemolysis in the development of clinical subphenotypes.Blood Rev. 2007;21(1):3747. 
7. Ballas SK. Pain management of sickle cell disease. Hematol/Oncol Clin Am. 2005;19(5):785-802.

8. Coluzzi PH, Schwartzberg L, Conroy JD, et al. Breakthrough cancer pain: a randomized trial comparing oral transmucosal fentanyl citrate (OTFC) and morphine sulfate immediate release (MSIR). Pain. 2001;91(1-2):123-130.

9. Ballas SK, Bauserman RL, McCarthy WF, Castro OL, Smith WR, Waclawiw MA; Investigators of the Multicenter Study of Hydroxyurea in Sickle Cell Anemia. Hydroxyurea and acute painful crises in sickle cell anemia: effects on hospital length of stay and opioid utilization during hospitalization, outpatient acute care contacts, and at home. J Pain Symptom Manage. 2010;40(6):870-882.

10. Mayer RA, Ringkamp M, Campbell JN, et al.. Peripheral mechanisms of cutaneous nociception. In: McMahon SB, Koltzenburg M, Eds. Wal and Melzack's Textboob of Pain, 5th ed. New York: Elsevier. 2006:9-34.

11. McMahon SB, Koltzenburg M, Eds. Wall and Melzack's Textbook of Pain, 5th ed. New York: Elsevier, 2006.

12. Fishman SM, Balantyne JC, Rathmell JP, Eds. Bonica's Management of Pain, 4th ed. Philadelphia: Lippincott Williams \& Wilkins, 2010.

13. Benjamin LJ. Nature and treatment of the acute painful episode in sickle cell disease. In: Steinberg MH, Ed. Disorders of Hemoglobin: Genetics, Pathophysiology, and Clinical Management. Cambridge: Cambridge University Press, 2001:671-710.

14. Benjamin LJ, Dampier CD, Jacox A, et al. Guideline for the management of acute and chronic pain in sickle cell disease. American Pain Society Clinical Practice Guidelines Series No. 1. Glenview, IL, 1999.

15. Ballas SK. Pain and sickle cell disease. In: Fishman SM, Balantyne JC, Rathmell JP, Eds. Bonica's Management of Pain, 4th ed. Philadelphia: Lippincott Williams \& Wilkins. 2010:806827.

16. Shaiova L, Wallenstein D. Outpatient management for sickle cell pain with chronic opioid pharmacotherapy. J Natl Med Assoc. 2004; 96(7):984-986.

17. Ballas SK. The treatment of pain in adults with sickle cell disease. Am J Hematol. 1990;34(1):49-54.

18. van Beers EJ, van Tuijn CF, Nieuwkerk PT, Friederich PW, Vranken JH, Biemond BJ. Patient-controlled analgesia versus continuous infusion of morphine during vaso-occlusive crisis in sickle cell disease, a randomized controlled trial. Am J Hematol. 2007; 82(11):955-960.

19. Chou R, Fanciullo GJ, Fine PG, et al.; American Pain Society-American Academy of Pain Medicine Opioids Guidelines Panel. Clinical guidelines for the use of chronic opioid therapy in chronic noncancer pain. J Pain. 2009;10(2):113-130.

20. Weissman DE, Haddox JD. Opioid pseudoaddiction —an iatrogenic syndrome. Clin J Pain. 1998;14(4):280-281.

21. Canfield MC, Keller CE, Frydrych LM, Ashrafioun L, Purdy CH, Blondell RD. Prescription opioid use among patients seeking treatment for opioid dependence. J Addict Med. 2010;4(2):108-113. 